\title{
Kajian Pengembangan Web HyLearn oleh Dosen Fakultas Ilmu Pendidikan Universitas Negeri Jakarta
}

\author{
${ }^{1}$ Universitas Negeri Jakarta, Jakarta, Indonesia. \\ ${ }^{2}$ Universitas Negeri Jakarta, Jakarta, Indonesia. \\ 3 Universitas Negeri Jakarta, Jakarta, Indonesia.
}

Adjmal, ${ }^{1 \otimes}$ Cecep Kustandi $^{2}$, Kunto Imbar Nursetyo ${ }^{2}$

DOI: https://doi.org/10.21009/JPI.o31.15

\begin{abstract}
Article History Abstract
Received : 2020

Accepted : 2002

Published : 2020

Penelitian ini bertujuan untuk melihat kajian pengembangan yang telah dilakukan oleh dosen Fakultas Ilmu Pendidikan, Universitas Negeri Jakarta. Penelitian ini menggunakan instrumen dalam bentuk kuisioner sebagai alat bantu pengumpulan data yang dikonstruksi dengan menggunakan pendekatan TPACK. Penelitian ini menggunakan

\section{Keywords} kerangka kerja TPACK versi $U D L$ dengan menggunakan 4 aspek (1) aspek teknologi, (2) aspek teknologi pedagogi, (3) aspek teknologi konten, (4) aspek teknologi pedagogi konten. Hasil yang didapat dijelaskan sesuai dengan aspek yang dikaji (1) aspek

Keywords 1; Survey 2; teknologi, sebagian (50\%) dosen telah mampu menggunakan HyLearn FIP untuk TPACK 3; UDL-TPACK 4; HyLearn 5; Teknologi Pendidikan kebutuhan perkuliahan, (2) aspek teknologi pedagogi, lebih dari sebagian (54\%) dosen mampu meningkatkan pengetahuan mengenai metode pengajaran dan pengetahuan mahasiswanya, (3) aspek teknologi konten, lebih dari sebagian $(60 \%)$ dosen mampu mengaplikasikan prinsip desain pesan pada konten yang dibuat, dipilih, atau digunakan, dan (4) aspek teknologi pedagogi konten, lebih dari sebagian (60\%) dosen mampu menciptakan pembelajaran online yang efektif dan efisien dengan mengkombinasikan konten, teknologi, dan metode pembelajaran yang tepat.
\end{abstract}

\section{Abstract}

This research aims to observe the development studies that has been implemented by the lecturers of faculty of education science Universitas Negeri Jakarta. This research uses the instrument in the form of questionare (cek lg bener ga kuesioner bing nya gitu wkwk) as a tools to gather the data which used TPACK approach. This research uses TPACK's framework with the IDL version that consist of 4 aspects (1) Technological aspect (2) Pedagogy technological aspect (3) Content technological aspect (4) Content of pedagogy technological aspect. The results are explained based on the used framwork as following (1) Tecnological aspect, a half of (50\%) lecturers are able to use Hylear web based for teaching needs (2) Pedagogy technological aspect, more than a half of (54\%) lecturers are able to improve the knowledge of teaching's methods as well as the students (3) Content Technological aspect, more than a half of $(60 \%)$ lecturers are able to implement instructional's principle design for the content that's made, choosen, or used (4) Content of pedagogy technological aspect, more than $(60 \%)$ lecturers are able to create online learning course that's effective and efficient with combining the content, technology, and appropriate instructional method.

\footnotetext{
$\bowtie$ Corresponding author : Adjmal Adress: Universitas Negeri Jakarta Jakata, Indonesia

E-mail: adjmalqd@gmail.com
} 


\section{PENDAHULUAN}

Era digital kerap kali ditandai dengan mulai banyak ditemukan penggunaan alat-alat elektronik pada hampir setiap aktivitas manusia. seperti halnya presentasi dalam perkuliahan dengan menggunakan $l c d$ projector. Namun untuk mencapai tahap tersebut pada era digital terdapat proses yang sangat panjang yang disebut sebagai revolusi industri. Revolusi industri merupakan perkembangan teknologi yang menyeluruh juga disertai dengan perubahan sosial ekonomi dan budaya.

Revolusi industri 4.0 masih terus berkembang hingga saat ini, bahkan mulai memasuki berbagai bidang dan aspek kehidupan. Salah satunya adalah bidang pendidikan, yakni suatu bidang yang memberikan kesempatan bagi masyarakat untuk mengembangkan potensi dirinya guna mendapatkan kecerdasan serta keterampilan dalam hidup bermasyarakat. Tidak berbeda dengan revolusi industri, pendidikan yang tersedia saat ini juga telah melalui tahapan seperti revolusi industri yang dinamakan dengna revolusi pendidikan. Dalam revolusi pendidikan tahapan-tahapan tersebut dibagi menjadi tiga tahap besar yang pada setiap tahapnya terdapat perubahan peran serta alat yang digunakan. Hal ini disebabkan karena munculnya teknologi yang lebih muktahir dan memberikan pengaruh terhadap metode pembelajaran yang mencakup rumusan tentang pengorganisasian bahan ajar, strategi penyampaian dan pengelolaan kegiatan dengan memperhatikan tujuan, hambatan dan karakteristik peserta didik sehingga diperoleh hasil yang efektif, efisien, dan menimbulkan daya tarik pembelajaran. ${ }^{1}$ Inilah yang disebut sebagai inovasi Pendidikan.

Salah satu contohnya adalah pembelajaran konvensional dengan cara ceramah di dalam ruang kelas yang mulai tergantikan dengan pembelajaran melalui web atau yang disebut sebagai online learning. Bahkan tak sedikit pula yang menggabungkan keduanya (hybrid learning) guna melengkapai kebutuhan belajar yang diperlukan.
Istilah e-learning pertama kali diperkenalkan oleh Universitas Illionis di Urbana-Champaign. Awalnnya diperkenalkan sebagai CBT (computer based training) pada tahun 1990-an dalam bentuk CD-ROM yang berisikan materi dalam bentuk tulisan maupun multimedia. Lalu, sejalan dengan perkembangan jaringan internet mulai muncul LMS (Learning Management System), guna memenuhi kebutuhan informasi yang sudah mampu didapat secara singkat tanpa dibatasi oleh ruang dan waktu.

Revolusi industri 4.0 datang tidak hanya membawa teknologi melainkan tatanan dan nilai baru. Kemunculannya bahkan memberikan dampak negatif terhadap nilai-nilai dalam masyarakat yang telah lama digunakan. Tak hanya itu, kemampuan dalam menggunakan ICT juga termasuk menjadi nilai baru untuk menghadapi revolusi industri 4.0, karena masyarakat tak lagi bersaing dengan sesamanya melainkan dengan teknologi-tekologi baru yang semakin pintar dan canggih.

Menristekdikti dalam (Syamsuar :2018) terdapat beberapa hal yang harus disiapkan untuk menghadapi revolusi industri 4.0 diantaranya : a) persiapan sistem pembelajaran yang lebih inovatif, untuk menghasilkan lulusan yang kompetitif dan terampil terutama dalam aspek data literacy, technological literacy and human literacy. B) rekonstruksi kebijakan kelembagaan pendidikan tinggi yang adaptif dan responsif terhadap revolusi industri 4.o dalam mengembangkan transdisiplin ilmu dan program studi yang dibutuhkan. C) persiapan sumber daya manusia yang responsive, adaptif dan handal untuk menghadapi revolusi industri 4.o. D) peremajaan sarana prasarana dan pembangunan infrastruktur pendidikan, riset, dan inovasi juga perlu dilakukan untuk menopang kualitas pendidikan, riset, dan inovasi.

Teknologi Pendidikan merupakan studi dan praktik etis dalam memfasilitasi belajar dan meningkatkan kinerja dengan membuat, menggunakan, dan memelihara proses serta sumber teknologi yang tepat. Dari definisi Teknologi Pendidikan diatas penelitian ini akan berfokus pada mengidentifikasi kajian pengebangan yang telah dilakukan oleh dosen dalam merancang perkuliahan melalui HyLearn 
dengan pola pemanfaatan yang dipilih guna melihat tingkat kesesuaiannya untuk digunakan dalam perkuliahan oleh mahasiswa melalui HyLearn FIP. Penelitian ini akan dilakukan dengan menggunakan penelitian survei terhadap pemanfaatan HyLearn dengan pola pemanfaatannya. Hasil kajian yang didapat beguna sebagai acuan untuk mengetahui kesiapan HyLearn dalam dimanfaatkan oleh dosen dan mahasiswa sebagai salah satu sumber belajar berbasis web.

\section{METODE}

Penelitian ini dilaksanakan di Fakultas Ilmu Pendidikan UNJ. Penelitian ini termasuk kedalam penelitian survey yang secara umum bertujuan untuk mengetahui kajian pengembangan yang dilakukan oleh dosen pada Fakultas Ilmu Pendidikan UNJ.

Menurut Mohen dan Nominon penelitian survey ialah salah satu dari jenis penelitian deskriptif yang mana penelitian survey merupakan kegiatan yang dilakukan dengan tujuan untuk mengumpulkan data pada saat tertentu. Dalam definisi ini dijelaskan bahwa penelitian survey merupakan suatu kegiatan mengumpulkan data yang mana data yang dimaksud adalah sebuah informasi. Dan informasi tersebut dikumpulkan ketika sedang dibutuhkan untuk suatu keperluan.

Sedangkan menurut Masri Singarimbun, penelitian survey adalah penelitian yang mengambil sampel dari satu populasi dan menggunakan kuesioner sebagai alat pengumpulan data yang pokok. ${ }^{2}$ Berdasarkan penjelasan tersebut dapat dijelaskan lebih mendalam tentang bagaimana penelitian survey dilakukan, yakni dengan mengumpulkan data dari sebagian objek penelitian dengan menggunakan sebuah alat instrumen guna memberikan kemudahan bagi peneliti dalam mengumpulkan data atau informasi.

Fraenkel dan Allen mengemukakan bahwa penelitian survey adalah penelitian yang mengumpulkan informasi dari suatu sampel dengan menanyakan melalui angket atau wawancara agar nantinya menggambarkan sebagian aspek dari populasi.

Untuk mengetahui kajian pengembangan oleh dosen Fakultas Ilmu Pendidikan UNJ maka model yang digunakan ialah dengan pendekatan TPACK dengan mengguakan UDL infused TPACK. UDL infused TPACK mampu meningkatkan kolaborasi antara pendidikan umum dan spesial dan mampu meningkatkan keberhasilan guru dalam mengajarkan beragam peserta didik dan siswa berkebutuhan khusus. Model TPACK yang dipadukan dengan prinsip UDL terletak pada potongan TPK, TCK, dan PCK guna memberikan kuasa pada guru dalam mendesain pembelajaran berbasis teknologi untuk semua peserta didik.

\section{Gambar 1.1 UDL infused TPACK}

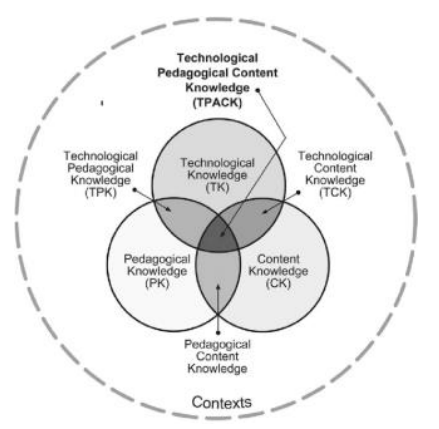

Dan berbeda dengan model yang diciptakan oleh Koehler dan Mishra model UDL infused TPACK dapat dikombinasikan dengan menggunakan ketiga aspek-aspek tersebut. Tidak perlu berurutan namun tetap saling berkaitan satu dengan lainnya. Tiap-tiap aspek beserta kombinasinya adalah sebagai berikut:
a. Technological Knowledge
b. Pedagogical Knowledge
c. Content Knowledge
d. Pedagogical Content Knowledge
e. Technological Content Knowledge
f. Technological Pedagogical Knowledge

HyLearn FIP merupakan salah satu sumber belajar terdapat pada Fakultas Ilmu Pendidikan UNJ. HyLearn FIP berwujud sebuah web yang memiliki tujuan untuk memfasilitasi pembelajaran online yang digunakan oleh mahasiswa dan dosen untuk seluruh program 
studi di Fakultas Ilmu Pendidikan UNJ. HyLearn FIP dikembangkan oleh tim dosen FIP yang diketua Bpk. Dr. Aip Badrujaman, M.Pd dari program studi BK dengan learning Instructional dan super admin oleh Bpk. Kunto Imbar S.Pd dari program studi Teknologi Pendidikan.

Portal HyLearn dibuat dengan menggunakan platform LMS Totara yang memiliki banyak keunggulan dalam melakukan pengelolaan kelas online dapat dilihat pada banyaknya fitur yang ditawarkan dan tampilan yang lebih mudah digunakan oleh pengguna.

Fakultas Ilmu Pendidikan dalam Universitas Negeri Jakarta merupakan unit pelaksana dalam bidang pendidikan dalam pembelajaran, penelitian, serta pengabdian pada masyarakat khususnya yang berhubungan dengan pengembangan ilmu pendidikan.

Dalam Fakultas Ilmu Pendidikan mengembangkan ilmu pendidikan dan keguruan dalam berbagai jenis jalur pendidikan serta berbagai jenjang pendidikan melalui pengkajian yang dilakukan pada setiap program studi, serta pusat studi dan atau laboratorium di lingkungan FIP UNJ.

Berikut merupakan berbagai program studi yang terdapat dalam Fakultas Ilmu Pendidikan Universitas Negeri Jakarta:

a. Bimbingan Konseling

b. Pendidikan Khusus

c. Pendidikan Masyarakat

d. Teknologi Pendidikan

e. Pendidikan Guru Sekolah Dasar

f. Pendidikan Guru PAUD

g. Manajemen Pendidikan

Fakultas Ilmu Pendidikan Universitas

Negeri Jakarta memiliki tujuan a) menghasilkan pendidik dan atau tenaga kependidikan yang professional di bidang Pendidikan Khusus, Pendidikan Anak Usia Dini, Sekolah Dasar, Bimbingan dan Konseling, Teknologi Pendidikan, Pendidikan Masyarakat, b) menghasilkan karya-karya penelitian dalam bidang pendidikan yang terpublikasikan dalam jurnal nasional yang terakreditasi dan internasional yang bereputasi, c) menghasilkan praktek terbaik berbasis hasil penelitian yang diimplementasikan melalui pengabdian masyarakat, d) menghasilkan jasa layanan pendidikan yang berkontribusi dalam mengatasi masalah pendidilkan masyarakat
Karakteristik dosen berbeda dengan mahasiswa yang mana mahasiswa termasuk kedalam digital native yang sudah terampil dalam memanfaatkan teknologi informasi dan komunikasi, dosen disebut sebagai digital immigrant yakni generasi yang belum familiar dengan penggunaan teknologi, informasi, dan komunikasi karena kelahiran era digital muncul pada tahun 1990-an. Oleh karena itu perlu dikaji lebih lanjut mengenai kajian pengembangan HyLearn oleh dosen FIP UNJ.

Tujuan khusus dalam penelitian ini yakni melakukan survei terhadap kajian pengembangan yang dilakukan oleh dosen dengan melihat kemampuan yang dimiliki dosen untuk mengembangkan course online pada web HyLearn FIP agar mampu digunakan oleh mahasiswa dengan efektif dan efisien.

Berdasarkan tujuan tersebut maka dapat kita jabarkan kedalam 4 aspek dengan menggunakan pendekatan TPACK yakni:

a. Aspek Teknologi.

b. Aspek Teknologi Pedagogi

c. Aspek Teknologi Konten

d. Aspek Teknologi Pedagogi Konten

Populasi dalam penelitian ini adalah dosen yang terdapat pada Fakultas Ilmu Pendidikan Universitas Negeri Jakarta. Pengambilan sampel menggunakan purposive sampling dengan kriteria (1) merupakan dosen Fakultas Ilmu Pendidikan UNJ, (2) Telah mengembangkan mata kuliah yang diampu menjadi course online pada web HyLearn FIP (3)Aktif dalam menggunakan HyLearn FIP untuk keperluan perkuliahan. Dengan begitu maka didapatkan sekitar 10 orang sampel.

Teknik pengambilan data dengan menyebarkan kuesioner yang berisi 15 pernyataan dengan 1 jawaban terbuka. Pernyataan terkait dengan aspek-aspek dari TPACK dan juga berkaitan dengan kajian pengembangan HyLearn. Sebelum menyebarkan kuesioner, kisi-kisi instruen dan instrument divalidasi terlebih dahulu kepada ahli.

Teknik analisis data untuk menganalisis hasil data yang telah diperoleh berupa kuantitatif yang selanjutnya diubah menjadi kualitatif. Hasil dari masing-masing indikator dapat dikategorikan berdasarkan persentase dengan menggunakan rumus dan indikator 
persentasi yang digunakan untuk mengolah data yaitu:

$$
\mathrm{P}=\mathrm{F} / \mathrm{N} \mathrm{X}{ }_{100} \%
$$

$\begin{array}{ll}\text { Keterangan: } & \\ \mathrm{P} & =\text { Persentase } \\ \mathrm{F} & =\text { Frekuensi jawaban dari } \\ & \text { responden } \\ \mathrm{N} & =\text { Jumlah responden } \\ \text { keseluruhan } & \end{array}$

Kemudian dari perhitungan tersebut akan diklasifikasikan menjadi indikator dengan menggunakan acuan sebagai berikut:

\begin{tabular}{cc}
\hline $\begin{array}{c}\text { Presetase } \\
\text { Jawaban }\end{array}$ & Keterangan \\
\hline $\mathbf{1 0 0} \%$ & Semua \\
$\mathbf{9 0} \%-\mathbf{9 9 , 9} \%$ & Hampir semua \\
$\mathbf{7 0} \% \mathbf{- 8 9 , 9} \%$ & Sebagian besar \\
$\mathbf{5 0 , 1} \%-\mathbf{6 9 , 9} \%$ & $\begin{array}{c}\text { Lebih dari } \\
\text { sebagian }\end{array}$ \\
\hline $\mathbf{5 0} \%$ & Sebagian \\
\hline $\mathbf{4 0} \%-\mathbf{4 9 , 9} \%$ & Hampir sebagian \\
\hline $\mathbf{2 0 , 1} \%-\mathbf{3 9 , 9} \%$ & Sebagian Kecil \\
\hline $\mathbf{0 , 1} \%-\mathbf{2 0} \%$ & Sedikit Sekali \\
\hline $\mathbf{0} \%$ & Tidak ada \\
\hline
\end{tabular}

\section{HASIL DAN PEMBAHASAN}

Penelitian yang dilakukan bertujuan untuk melihat kajian pengembangan yang dilakukan oleh dosen dengan melihat kemampuan yang dimiliki dosen untuk mengembangkan course online pada web HyLearn FIP agar mampu digunakan oleh mahasiswa dengan efektif dan efisien. Data pada penelitian ini didapat dengan menggunakan instrumen berupa kuisioner yang dikonstruk dengan menggunkan pendekatan TPACK.

Data yang diperoleh dari penelitian ini didapat dari penyebaran kuisioner pada dosen
Fakultas Ilmu Pendidikan sebanyak 10 orang dengan kriteria telah mengembangkan course online dan aktif dalam melakukan perkuliahan melalui web HyLearn.

Berikut adalah deskripsi data yang telah diperoleh berdasarkan aspek serta indikator yang akan dinilai:

\section{Tabel Nilai Akhir Hasil Kuisioner}

\begin{tabular}{ccccccc}
\hline $\begin{array}{c}\text { Bentuk } \\
\text { Instrumen }\end{array}$ & \multicolumn{3}{c}{ Jawaban } & & Jumlah \\
\cline { 1 - 6 } Kuisioner & SS & S & N & TS & STS & \\
& 37 & 82 & 20 & 11 & 0 & 150 \\
Persentase & $24,67 \%$ & $54,67 \%$ & $13,33 \%$ & $7,33 \%$ & $0 \%$ & $100 \%$ \\
\hline
\end{tabular}

Berdasarkan tabel diatas maka dapat disimpulkan bahwa sebagian kecil dosen $(24,67 \%)$ menjawab dengan 'Sangat Setuju', lebih dari sebagian $(54,67 \%)$ menjawab dengan 'Setuju', sedikit sekali (13,33\%) menjawab 'Netral', sedikit sekali $(7,33 \%)$ menjawab 'Tidak Setuju', dan tidak ada (o\%) menjawab 'Sangat Tidak Setuju'. Dengan begitu dapat ditarik kesimpulan bahwa lebih dari sebagian $(54,67 \%)$ dosen mampu mengembangkan course online pada web HeyLearn FIP dengan efektif dan efisien.

Berikut merupakan data-data yang diporelah berdasarkan aspek dam imdikator yang terdapat dalam instrument penelitian yang telah dikembangkan dengan menggunakan pendekatan TPACK:

Pertama terdapat aspek teknologi Dalam aspek teknologi terdapat tiga indikator didalamnya yakni meliputi kemudahan mengakses web HyLearn FIP, penggunaan web HyLearn FIP, dan HyLearn FIP sebagai sumber belajar yang tepat. 
Tabel Hasil Jawaban Kuisioner pada Aspek Teknologi

\begin{tabular}{ccccccc}
\hline $\begin{array}{c}\text { Bentuk } \\
\text { Instrumen }\end{array}$ & & & & & & \\
\cline { 1 - 5 } Kuisioner & SS & S & N & TS & STS & \\
& 12 & 25 & 4 & 9 & 0 & 50 \\
Persentase & $24 \%$ & $50 \%$ & $8 \%$ & $18 \%$ & $0 \%$ & $100 \%$ \\
\hline
\end{tabular}

Berdasarkan tabel 4.2 diatas maka dapat disimpulkan bahwa sebagian kecil (24\%) dosen menjawab menjawab dengan 'Sangat Setuju', sebagian (50\%) menjawab dengan 'Setuju', sedikit sekali (8\%) menjawab 'Netral', sedikit sekali (18\%) menjawab 'Tidak Setuju', dan tidak ada (o\%) yang menjawab 'Sangat Tidak Setuju'. Dengan begitu dapat ditarik kesimpulan bahwa sebagian (50\%) dosen mampu mengembangkan course online pada web HeyLearn FIP dengan efektif dan efisien apabila dilihat dari aspek teknologi.

Kedua, dalam aspek teknologi pedagogi terdapat tiga indikator didalamnya yakni meliputi pengembangan course online guna meningkatkan pengetahuan, membangun motivasi belajar, panduan belajar untuk pembelajaran course online, dan assessment untuk pembelajaran course online.

Tabel Hasil Jawaban Kuisioner untuk Aspek Teknologi Pedagogi

\begin{tabular}{ccccccc}
\hline $\begin{array}{c}\text { Bentuk } \\
\text { Instrumen }\end{array}$ & \multicolumn{3}{c}{ Jawaban } & & Jumlah \\
\cline { 1 - 5 } Kuisioner & SS & S & N & TS & STS & \\
& 15 & 27 & 6 & 2 & 0 & 50 \\
Persentase & $30 \%$ & $54 \%$ & $12 \%$ & $4 \%$ & $0 \%$ & $100 \%$ \\
\hline
\end{tabular}

Berdasarkan tabel diatas maka dapat disimpulkan bahwa sebagian kecil (30\%) dosen menjawab menjawab dengan 'Sangat Setuju', lebih dari sebagian (54\%) menjawab dengan 'Setuju', sedikit sekali (12\%) menjawab 'Netral', sedikit sekali (4\%) menjawab 'Tidak Setuju', dan tidak ada (o\%) yang menjawab 'Sangat Tidak
Setuju'. Dengan begitu dapat ditarik kesimpulan bahwa lebih dari sebagian (54\%) dosen mampu mengembangkan course online pada web HeyLearn FIP dengan efektif dan efisien apabila dilihat dari aspek teknologi pedagogi.

Ketiga adalah aspek teknologi
konten. Dalam aspek teknologi konte
terdapat dua indikator didalamnya yakni
meliputi pemahaman terhadap prinsip desain
pesan dan pemilihan jenis media
pembelajaran.

Tabel Hasil Jawaban Kuisione pada Aspek Teknologi Konten

\begin{tabular}{ccccccc}
\hline $\begin{array}{c}\text { Bentuk } \\
\text { Instrumen }\end{array}$ & & & & & & Jumlah \\
\cline { 1 - 5 } Kuisioner & SS & $\mathrm{S}$ & $\mathrm{N}$ & $\mathrm{TS}$ & $\mathrm{STS}$ & \\
& 9 & 24 & 7 & $\mathrm{0}$ & $\mathrm{0}$ & 40 \\
Persentase & $22,5 \%$ & $60 \%$ & $17,5 \%$ & $0 \%$ & $0 \%$ & $100 \%$ \\
\hline
\end{tabular}

Berdasarkan tabel diatas maka dapat disimpulkan bahwa sebagian kecil $(22,5 \%)$ dosen menjawab menjawab dengan 'Sangat Setuju', lebih dari sebagian (6o\%) menjawab dengan 'Setuju', sedikit sekali $(17,5 \%)$ menjawab 'Netral', tidak ada (o\%) yang menjawab 'Tidak Setuju', dan 'Sangat Tidak Setuju'. Dengan begitu dapat ditarik kesimpulan bahwa lebih dari sebagian (6o\%) dosen mampu mengembangkan course online pada web HeyLearn FIP dengan efektif dan efisien apabila dilihat dari aspek teknologi konten.

Terakhir terdapat aspek teknologi pedagogi konten. Dalam aspek teknologi pedagogi konten terdapat hanya satu indikator didalamnya yakni pemahaman terhadap konten, teknologi, dan metode pengajaran.

Tabel Hasil Jawaban Kuisioner untuk Aspek Teknologi Pedagogi Konten 


\begin{tabular}{ccccccc}
\hline $\begin{array}{c}\text { Bentuk } \\
\text { Instrumen }\end{array}$ & & & & & & \\
\cline { 1 - 5 } Kuisioner & SS & S & N & TS & STS & \\
& 1 & 6 & 3 & 0 & 0 & 10 \\
Persentase & $10 \%$ & $60 \%$ & $30 \%$ & $0 \%$ & $0 \%$ & $100 \%$ \\
\hline
\end{tabular}

Berdasarkan tabel diatas maka dapat disimpulkan bahwa sedikit sekali (10\%) dosen menjawab menjawab dengan 'Sangat Setuju', lebih dari sebagian (6o\%) menjawab dengan 'Setuju', sebagian kecil (30\%) menjawab 'Netral', tidak ada (o\%) yang menjawab 'Tidak Setuju', dan 'Sangat Tidak Setuju'. Dengan begitu dapat ditarik kesimpulan bahwa lebih dari sebagian (6o\%) dosen mampu mengembangkan course online pada web HeyLearn FIP dengan efektif dan efisien apabila dilihat dari aspek teknologi konten.

\section{SIMPULAN}

Untuk mencapai tujuan khusus tersebut perlu memperoleh data penelitian dengan menggunakan model atau pendekatan tertentu. Pada penelitian ini menggunakan bantuan instrumen dalam bentuk kuisioner yang dibuat dengan menggunakan pendekatan TPACK. Oleh karena itu peneliti akan coba memaparkan kesimpulan berdasarkan dengan tujuan khusus yang sebelumnya telah disebutkan. Berikut merupakan simpulan berdasarkan tujuan khusus penelitian ini:

1. Aspek Teknologi

Simpulan dari tujuan khusus ini dapat dilihat dengan sebagian dosen yang telah mampu mengidentifikasi penggunaan HyLearn FIP untuk keperluan perkuliahan meliputi penguasaan teknologi dan analisis dalam mempertimbangkan HyLearn dalam menciptakan pembelajaran yang efektif dan efisien.

2. Aspek Teknologi Pedagogi

Simpulan dari tujuan khusus ini dapat dilihat dengan lebih dari sebagian dosen telah mampu meningkatkan pengetahuan dosen mengenai metode pengajaran yang lebih efektif dan efisien serta memberikan mahasiswa kebermaknaan belajar yang lebih baik

3. Aspek Teknologi Konten

Simpulan dari tujuan khusus ini dapat dilihat dengan lebih dari sebagian dosen telah mampu memilih, menciptakan, dan menggunakan berbagai macam konten yang sesuai dengan prinsip desain pesan.

4. Aspek Teknologi Pedagogi Konten

Simpulan dari tujuan khusus ini dapat dilihat dengan lebih dari sebagian dosen telah mampu mengembangkan pembelajaran dengan mengkombinasikan konten, teknologi, dan metode pembelajaran guna menciptakan pembelajaran online yang efektif dan efisien.

Berdasarkan ketercapaian pada tiap tujuan khusus pada penelitian ini apabila melihat tujuan umum yaitu untuk melihat kajian pengembangan yang telah dilakukan oleh dosen fakultas ilmu pendidikan maka dapat disimpulkan bahwa lebih dari sebagian dosen mampu menciptakan pembelajaran yang lebih efektif dan efisien dengan menggunakan course online pada web HyLearn FIP

\section{UCAPAN TERIMA KASIH}

Penulis mengucapkan terima kasih kepada Ibu Dr. Sofia Hartati, M.Si selaku Dekan Fakultas Ilmu Pendidikan Universitas Negeri Jakarta dan Bapak Anan Sutisna, M.Pd selaku wakil Dekan I Fakultas Ilmu Pendidikan UNJ. Penulis juga berterimakasih kepada semua staff dan dosen Program Studi Teknologi Pendidikan yang telah banyak membantu penulis sehingga skripsi ini dapat terwujud yaitu Ibu Retno Widyaningrum, S. Kom, MM selaku koordinator Program Studi Teknologi Pendidikan UNJ Bapak Cecep Kustandi M.Pd selaku dosen pembimbing 1, Bapak Kunto Imbar Nursetyo M.Pd selaku dosen pembimbing 2. Penulis juga ingin berterima kasih kepada Ibu Suprayekti selaku validator dan telah memberi banyak bantuan dan masukan dalam skripsi penulis. 


\section{DAFTAR PUSTAKA}

Arikunto Suharsimi dan Safruddin Cept. 2009. Evaluasi Program Pendidikan. Jakarta: PT Asdi Mahasatya

Kaswan. 2013. Pelatihan dan Pengembangan untuk Meningkatkan Kinerja SDM. Bandung: Alfabeta

Slameto. 2001. Dasar-dasar Evaluasi Pendidikan. Jakarta: PT. Bumi Aksara

Sukardi. 2014. Evaluasi Program Pendidikan dan Kepelatihan. Jakarta: Bumi Aksara

Wirawan. 2011. Evaluasi: Teori, Model, Standar, Aplikasi dan Teori. Jakarta: Raja Grafindo

John W. Creswell. 2011. Research Design.

Yogyakarta; Pustaka Pelajar

Sukardi. 2009. Metodologi Pendidikan Kompetensi dan Praktiknya. Jakarta: Bumi Aksara

Masri Singarimbun \& Sofia Effendi. 1989. Metode Penilitian Survei. Jakarta: LP3ES

Nurul Zuriah. 2009. Metode Penelitian Sosial dan Pendidikan. Jakarta: Bumi Aksara

Hamid Darmadi, M.P. 2014. Dimensi-Dimensi Metode Penelitian Pendidikan dan Sosial. Bandung: Alfabeta

Dewi S. Prawiradilaga. 2012. Wawasan Teknologi Pendidikan. Jakarta: Kencana Prenada Media Group

Nana S. Sukmadinata. 2012. Metode Penelitian Pendidikan. Bandung: PT Remaja Rosdakarya

Waluyo. 2008. Akuntansi Pajak. Jakarta: Salemba Empat

Abdul Ghafur. 1986. Desain Instruksional; Sebuah langkah sistematis penyusunan pola dasar kegiatan belajar dan mengajar. Solo: Tiga Serangkai

Mary C. Herring. 2016. Handbook of Tecknological Pedagogical Content Knowledge (TPACK) for Educators Second Edition. New York: Routledge

Yanti Yusman, "Meningkatkan Proses Belajar Mengajar dengan Menggunakan Sistem ELearning Studi Kasus SMP Negeri 24 Padang", 2017

Syamsuar dan Reflianto, "Pendidikan dan Tantangan Pembelajaran Berbasis Teknologi Informasi di Era Revolusi Industri 4.0", 2018

Sri Sukaesi, et al, "Analisis Kemampuan Technological Pedagogic and Content Knowledge (TPACK) Calon Guru Pada Mata Kuliah PP Bio", Prosiding Seminar Nasional Pendidikan Sains (SNPS), 2017
Valentina Arkorful dan Nelly Abaidoo, "The Role of E-Learning, Advantages and Disadvantages of its Adoption in Higher Education", 2015, hal. 34 